\title{
РЕЦЕНЗИЯ НА ЭКСПЕРТИЗУ КАК ДОКАЗАТЕЛЬСТВО В ГРАЖДАНСКОМ И АРБИТРАЖНОМ ПРОЦЕССЕ
}

\section{REVIEW OF EXPERTISE AS EVIDENCE IN CIVIL AND ARBITRATION PROCEEDINGS \\ O. Ryabova \\ N. Kuznetsova}

Summary: This article analyzes the essence and significance of the review of expertise in the judicial process. The authors consider the review as a full-fledged written evidence, which allows the participants of the trial and the court to resolve the existing doubts in the most effective way due to the reviewer's objective assessment of the expert opinion. The authors point out that the review of the expert examination has the right to be accepted by the courts as evidence along with other evidence specified in the procedural legislation.

Keywords: review, evidence, examination, written evidence, reviewer.

\author{
Рябова Ольга Алексеевна \\ Преподаватель, ФКОУ ВО «Владимирский юридический \\ uнстumym ФСИН России» \\ frau.lelya2012@yandex.ru \\ Кузнецова Наталья Владимировна \\ старший преподаватель, ФКОУ ВО «Владимирский \\ юридический институт ФСИН России» \\ kuznezova-1963@mail.ru
}

Аннотация: Настоящая статья анализирует сущность и значение рецензии на экспертизу в судебном процессе. Авторы рассматривают рецензию как полноценное письменное доказательство, которое дает возможность участникам судебного процесса и суду наиболее эффективным способом разрешить имеющиеся сомнения благодаря объективной оценке рецензентом экспертного заключения. Авторы указывают, что рецензия на экспертизу имеет право приниматься судами в качестве доказательства наряду с другими доказательствами, указанными в процессуальном законодательстве.

Ключевые слова: рецензия, доказательства, экспертиза, письменное доказательство, рецензент.

не застрахован от ошибок или вмешательства факторов, которые могут позволить говорить об экспертизе как о ненадлежащем доказательстве. Так, экспертами могут быть допущены процессуальные, гносеологические и деятельностные ошибки, которые впоследствии приведут к даче неэффективного с точки зрения доказательства или ошибочного экспертного заключения.

Судебная практика часто сталкивается с экспертными заключениями, данные которых подвергаются сомнению со стороны участников процесса. Это связано, в частности, как с не всегда должным качеством произведенной экспертизы, так и с необходимостью разъяснения отдельных моментов экспертного заключения лицом, обладающим, в отличие от участников процесса, специальными познаниями в той или иной области.

Необходимо отметить, что судебная практика предполагает, что стороны, несогласные с выводами экспертизы, ходатайствуют о проведении повторной экспертизы в соответствии с положениями, предусмотренными процессуальным законодательством Российской Федерации.[1,2]. Однако, для того, чтобы такое ходатайство имело шанс на удовлетворение, сторона процесса обязана обосновать необходимость данного процессуального действия. Это и является серьезным препятствием к установлению истины с помощью повторной экспертизы. Учитывая тот факт, что стороны процесса не обладают специальными познаниями в исследуемых экспертизами областях, предъявить суду какие-либо серьезные 
обоснования они не могут. В свою очередь судья, объективно не являясь профессионалом в той или иной области, зачастую, также не может подтвердить или опровергнуть выводы эксперта. Кроме этого, нередко, суды скептически относятся к вызываемым в суд всевозможным специалистам в исследуемой области, которые привлекаются сторонами для обоснования заявленного ходатайства и охотнее прислушиваются к выводам официального экспертного заключения. В результате нередки случаи отказа судом в удовлетворении ходатайства о назначении повторной либо комиссионной экспертизы.

В связи с этим мы считаем, что профессиональную, непредвзятую оценку, имеющемуся в распоряжении суда экспертному заключению, должен давать только эксперт в рассматриваемой области, обладающий необходимым образованием, квалификацией и допуском к производству того или иного вида экспертиз. Только такое лицо может эффективно и грамотно оценить имеющееся экспертное заключение и представить суду свои выводы в виде рецензии, которая представляет собой письменный анализ имеющейся экспертизы, проводимый с целью установления достоверности и обоснованности последней. Полагаем, что данные требования к рецензенту необходимы для исключения сомнений у суда и участников процесса к его компетенции.

Рецензия на экспертизу является тем правовым инструментом, который способен поставить под сомнение выводы экспертного заключения. Это, в свою очередь, даст реальную возможность избежать негативных последствий ошибочной экспертизы и принятия незаконного решения судом. Таким образом, с точки зрения обоснования ходатайства о назначении повторной или комиссионной экспертизы процессуально рецензия будет являться инструментом доказывания. Так, в частности, Определением Судебной коллегии по экономическим спорам Верховного Суда РФ от 25.01.2018 по делу № 305-ЭС 17-11486, А40-73410/2015 указано на неправомерность отказа суда нижестоящей инстанции в проведении повторной экспертизы, отсутствие оценки и неприобщение к делу рецензии на экспертизу в качестве доказательства, являющегося обоснованием для проведения повторной экспертизы.

Вместе с тем, говоря о рецензии, необходимо отметить обратную ее цель, связанную с оценкой результатов экспертизы.

Как мы уже указывали выше, рецензия может явиться и средством, подтверждающим выводы экспертизы, произведенной в рамках рассматриваемого гражданского или арбитражного дела по инициативе сторон участников процесса или суда.

В этом случае выводы эксперта-рецензента не толь- ко добавляют убедительности выводам имеющегося экспертного заключения и облегчают суду работу по объективной оценке экспертизы как доказательства по делу, но и избавляют дело и процесс его рассмотрения от загромождения сомнительными, зачастую необоснованными и противоречивыми материалами, претендующими на статус доказательств.

Необходимо отметить, что процесс рассмотрения судом соответствующих ходатайств и производство экспертизы, в случае их удовлетворения, процесс длительный и дорогостоящий. И, если последнее полностью возложено на сторону, ходатайствующую об экспертизе, то приостановление производства по делу при назначении повторной экспертизы, предусмотренное в таких случаях процессуальным законодательством, неизбежно связано с несением сторонами дополнительных расходов, негативными последствиями для хозяйствующих субъектов, связанными с затягиванием судебного процесса, дополнительной нагрузкой на судебную систему, которая и без того чрезмерна, что не добавляет качества правосудию.

В свете вышесказанного обращение к такому правовому инструменту как рецензия на экспертное заключение должно расцениваться сторонами и судом как возможность наиболее объективной оценки в отношении такого специфического доказательства как экспертиза, а впоследствии и установления истины в рассматриваемом споре.

Вместе с тем, мы хотим отметить, что рецензия на экспертизу не должна нести в себе правовую оценку заключения эксперта, так как это является исключительным правом суда.

Процессуальным законодательством отдельно не выделен в качестве доказательства такой правовой инструмент как рецензия. Однако, это не исключает возможность ее приобщения в дело в качестве доказательства. Имеющимся законодательством предусматриваются письменные доказательства, которые могут быть предоставлены в качестве таковых для обоснования сторонами позиции по делу. [1,2]. Исходя из понятия рецензии, она является письменным документом, а, следовательно, относится к письменным доказательствам и средствам доказывания.

Вместе с тем, рецензия на экспертизу, представляемая стороной, принимается судьями крайне осторожно либо не принимается вовсе в качестве обоснования сторонами тех или иных фактов. Суды при предъявлении одной из сторон процесса рецензии на экспертизу в качестве доказательства, достаточно часто отказывают в приобщении данного документа в дело, мотивируя это тем, что рецензия не может считаться доказательством, 
отвечающим признакам допустимости либо указывают на то, что эксперт, изготавливающий рецензию не предупреждался судом об ответственности за дачу заведомо ложных показаний.

Эта позиция судейского сообщества, за редким исключением, вызывает недоумение, поскольку остается непонятным по какой причине письменная рецензия не может относится к доказательствам, которые указаны в ГПК РФ и АПК РФ как допустимые. Тем более, что на настоящий момент времени появилась положительная судебная практика по данному вопросу. Так, примером может служить Определение CK по гражданским делам Верховного Суда РФ от 27 октября 2020 г. №18-КГ20-57-К4 по делу № 2-979/2019, в котором суд признал противоречащим нормам материального и процессуального права выводы судов нижестоящих инстанций о недопустимости рецензии как письменного доказательства. Высшая судебная инстанция указала на то, что выводы судов о недопустимости рецензии как доказательства ведут к ограничению права стороны на обоснование своих доводов.

Таким образом, мы можем утверждать, что отказ судей принимать рецензию на судебную экспертизу в качестве доказательства ведет к нарушению принципа состязательности сторон.

В свете вышеуказанного, представляется излишним предложение некоторых авторов [8] о введении в процессуальное законодательство РФ специальных норм и придании рецензии, наряду с экспертизой, отдельного правового статуса, поскольку суть рецензии как письменного доказательства охватывается смыслом, изложенным в ст. 71 ГПК РФ и ст. 75 АПК РФ

Подводя итог, мы можем констатировать, что рецензия на судебную экспертизу является неотъемлемым правовым инструментом, который может и должен быть использован сторонами и судом в целях достижения эффективности правосудия и установления истины по делу.

\section{ЛИТЕРАТУРА}

1. Гражданский процессуальный кодекс Российской Федерации от 14 ноября 2002 г. №138-Ф3 // Собрание законодательства Российской Федерации от 18 ноября 2002 г. №462, ст.4532.

2. Арбитражный процессуальный кодекс Российской Федерации от 24 июля 2002 г. №95-Ф3 // Собрание законодательства Российской Федерации от 29 июля 2002 г №30, ст.3012.

3. Федеральный закон от 31 мая 2001 г. N 73-Ф3 «0 государственной судебно-экспертной деятельности в Российской Федерации» (с изменениями и дополнениями) // Российская газета от 5 июня 2001 г. № 106

4. Определение СК по гражданским делам Верховного Суда РФ от 27 октября 2020 г. N 18-КГ20-57-К4 // СПС «Гарант»

5. Определение Судебной коллегии по экономическим спорам Верховного Суда РФ от 25.01.2018 по делу № 305-ЭС17-11486, А40-73410/2015 // СПС «Гарант»

6. Саханова Т.С. Судебная экспертиза - М. - Городец: Формула права, - 1999. - С.365

7. Россинская Е.С. Судебная экспертиза в гражданском, арбитражном, административном и уголовном процессе (изд. 3 доп.), - М. - Норма Инфра $M,-2014,-C .736$

8. Линев А.Н. К вопросу о процессуальном статусе рецензии на заключение эксперта // Вестник Московского университета МВД России. - 2020. - №1. C. $118-120$

( Рябова Ольга Алексеевна (frau.lelya2012@yandex.ru), Кузнецова Наталья Владимировна (kuznezova-1963@mail.ru). Журнал «Современная наука: актуальные проблемы теории и практики» 